\title{
Neural and Cognitive Markers and Regulation of Emotion in Depression: A Mini-Review and a Short Case Report
}

\author{
Gonçalves Eduardoํㅜ, Moniz Marco ${ }^{2}$, Pertega-Gomes Alexandre1 \\ ${ }^{1}$ Psychiatry at Centro Hospitalar Universitário do Algarve, Faro, Portugal \\ ${ }^{2}$ Clinical Psychology at Centro Hospitalar Universitário do Algarve, Faro, Portugal \\ Email: eduar.goncalves@gmail.com
}

How to cite this paper: Eduardo, G., Marco, M. and Alexandre, P.-G. (2017) Neural and Cognitive Markers and Regulation of Emotion in Depression: A Mini-Review and a Short Case Report. Open Journal of Psychiatry, 7, 365-373.

https://doi.org/10.4236/ojpsych.2017.74030

Received: August 24, 2017

Accepted: September 27, 2017

Published: September 30, 2017

Copyright (c) 2017 by authors and Scientific Research Publishing Inc. This work is licensed under the Creative Commons Attribution International License (CC BY 4.0).

http://creativecommons.org/licenses/by/4.0/

\begin{abstract}
In the presented short clinical case of depression, the constructs of Research Domain Criteria (RDoC) of loss (negative valence systems) and cognitive control (cognitive systems) have been operationalized. It has been concluded that a normal cognitive control of emotion, requiring the functional and structural integrity of prefrontal cortex (PFC) and orbitofrontal cortex (OFC), is lacking in depression, but its amelioration can be achieved through the implementation of cognitive remediation/rehabilitation programs. A mini-review on neural and cognitive markers and regulation of emotion in depression is previously presented.
\end{abstract}

\section{Keywords}

Executive Function, Cognitive Control of Emotion, Loss, Dorsolateral Prefrontal Cortex (DLPFC), Orbitofrontal Cortex (OFC), Neural and Cognitive Markers in Depression, Research Domain Criteria (RDoC)

\section{Executive Function and Its Neural Correlates and Dysregulation of Emotion in Depression}

Executive function (EF) is related with prefrontal cortex (PFC), and is studied through the assessment of cognitive control, working memory and emotional decision making. Cognitive control is measured by switching tasks that have in common the need of conflict resolution, involving the inhibition of a pre-potent response, due to over-learned previous response, in Stroop Task (ST), or due to being primed as part of the experimental procedure, in Wisconsin card sorting test (WCST). Working memory tasks require holding information in working 
memory, such as Corsi block test, Tower of Hanoi/London (TOL). The emotional decision making tasks, such as the Iowa gambling task (IGT), require that participants weigh, toward a specific goal, the relative contributions of rewards and punishments. A tripartite model of EF includes the abilities to form, maintain and shift mental set. Mental set formation, through planning, using focused attention, generativity, memory retrieval, working memory, sequencing, requires the integrity of dorsolateral PFC (DLPFC), whose lesion determines a disorganized neuro-behavioral syndrome. Mental set maintenance, through implementation/monitoring, using response initiation, response selection and conflict resolution, selective attention, self-monitoring and attentional vigilance, requires the integrity of superior medial PFC, whose lesion determines an apathetic neurobehavioral syndrome. Mental set maintenance, through social appropriateness, using response inhibition and discrepancy detection, requires the integrity of ventral medial PFC (ventral MPFC) and orbitofrontal cortex (OFC), whose lesion determines a disinhibited or psychopathic neurobehavioral syndrome. Mental set shifting, through problem solving, using discrepancy detection, cognitive flexibility, attentional shifting, generativity, memory retrieval and working memory, requires the integrity of DLPFC, whose lesion also determines a perseverative neurobehavioral syndrome [1] [2]. Deficit in inhibition of negative stimuli processing is related with difficulty in reappraising [3] [4], decreased cognitive flexibility is associated with rumination [5], and normal executive function is related with a frequent use of reappraisal (compared to expressive suppression) [6]. The function of cognitive control network (CCN), which includes the dorsal anterior cingulate cortex (dACC), DLPFC and posterior parietal regions [7], may be critical to reappraisal, through the allocation of resources to goal directed behaviors it facilitates. The dACC is involved in detection and monitoring of affective and non-affective stimuli and the ventral/rostral ACC primarily works with the posterior parietal and DLPFC regions of the CCN to regulate affective responses [8]; the DLPFC is involved in the interpretation's modulation of processed information from emotion perception regions [9]-[14]. The generation and experience of emotions depend on subcortical (amygdala, ventral striatum, periaqueductal gray matter) and limbic structures (dACC, anterior insula), and their regulation is concretized by CCN, ventrolateral PFC and MPFC [8]. The default mode network of brain function (DMN) includes the precuneus/posterior cingulate cortex, parietal cortex and MPFC [15] [16]. Patients with major depressive disorder ruminate and use reappraisal less often than healthy controls [17], and inefficient emotion regulation can predict subsequent depression relapse and severity [18] [19]. During depression's state, the hypoconnectivity of CCN predicts deficit in remission following pharmacotherapy [20] [21] [22] [23]. In depression, abnormal connectivity of MPFC with posterior aspects of the DMN is relate with overgeneralized autobiographical memory (and its contribution to negative bias about past life experiences), and abnormal connectivity of anterior aspects of the DMN (ventral MPFC) is related 
with negative self-referential processing (rumination, guilt, negative bias) [9]-[14], [24] [25] [26] [27]. The deficits of the neural networks which sustain regulatory functions of cognition are frequent in various psychiatric disorders [28], and, according to Lantrip and Huang, pre-illness emotion dysregulation is a marker of underlying $\mathrm{CCN}$ and DMN alteration that later may manifest as affective or cognitive illness [29].

\section{Clinical Case}

A 44-year-old, right-handed, female, Portuguese patient, with 9 years of schooling, complained of depressive symptoms. Informed consent from the patient has been obtained, regarding namely the therapeutic intervention she has been subjected and the scientific presentation of her clinical case. She completed the demographic and symptom questionnaire, which included the 17 item-Hamilton Depression Rating Scale (HAM-D-17) [30] and the Personality Diagnostic Questionnaire-4 [31], and performed the Portuguese version of computerized tasks, from PEBL [32]: TOL [33]; IGT [34]; Victoria ST [35]; WCST and FT [36] [37]. At the time of the first assessment (at "time 1"), the patient presented significant depressive symptoms and suicidal ideation and intention, as well as avoidant personality traits. She didn't present a history of bipolar depression, schizophrenia or previous psychotic symptoms, nor meet the diagnostic criteria for neurodegenerative disease, substance abuse, neurological disease or traumatic brain injury, as categorized by the $10^{\text {th }}$ revision of the International Classification of Diseases, from World Health Organization, and the $5^{\text {th }}$ edition of the Diagnostic and Statistical Manual of Mental Disorders, from American Psychiatric Association (DSM-5). DSM-5 diagnostic criteria for major depressive disorder include: 1) five (or more) of the following symptoms have been present during the same 2-week period and represent a change from previous functioning (noting that, at least, one of the symptoms is either depressed mood or loss of interest or pleasure): depressed mood most of the day, nearly every day, as indicated by either subjective report or observation made by others; markedly diminished interest or pleasure in all, or almost all, activities most of the day, nearly every day; significant weight loss when not dieting or weight gain or decrease or increase in appetite nearly every day; insomnia or hypersomnia nearly every day; psychomotor agitation or retardation nearly every day; fatigue or loss of energy nearly every day; feelings of worthlessness or excessive or inappropriate guilt nearly every day; diminished ability to think or concentrate, or indecisiveness, nearly every day; recurrent thoughts of death, recurrent suicidal ideation without a specific plan, or a suicide attempt or a specific plan for committing suicide; 2) the symptoms cause clinically significant distress or impairment in social, occupational or other important areas of functioning; 3 ) the episode is not attributable to the physiological effects of a substance or to another medical condition (noting that criteria 1 - 3 represent a major depressive episode, and responses to a significant loss, i.e., bereavement, financial ruin, losses from a natural disaster, a 
serious medical illness or disability) may include the feelings of intense sadness, rumination about the loss, insomnia, poor appetite, and weight loss noted in criterion A, which may resemble a depressive episode, and, although such symptoms may be understandable or considered appropriate to the loss, the presence of a major depressive episode in addition to the normal response to a significant loss should also be carefully considered, requiring this decision inevitably the exercise of clinical judgment based on the individual's history and the cultural norms for the expression of distress in the contest of loss); 4) the occurrence of the major depressive episode is not better explained by schizoaffective disorder, schizophrenia, schizophreniform disorder, delusional disorder, or other specified and unspecified schizophrenia spectrum and other psychotic disorders; 5) there has never been a manic episode or a hypomanic episode. DSM-5 diagnostic criteria for mild neurocognitive disorder (NCD) include: the evidence of modest cognitive decline from a previous level of performance in one or more cognitive domains-complex attention, executive function, learning and memory, language, perceptual motor, or social cognition-based on concern of the individual, a knowledgeable informant, or the clinician that there has been a mild decline in cognitive function; the evidence of modest impairment in cognitive performance preferably documented by standardized neuropsychological testing or, in its absence, another quantified clinical assessment; the absence of interference of the cognitive deficits with capacity for independence in everyday activities (but greater effort, compensatory strategies, or accommodation may be required). Concerning the present case differential diagnosis, the NCD category encompasses the group of disorders in which the primary clinical deficit is in cognitive function, and that are acquired rather than developmental, thus representing a decline from a previously attained level of functioning. Cognitive deficits are present in (many if not) all mental disorders, but only disorders whose core features are cognitive are included in the NCD category. Patients with depression and "reversible" NCD exhibit more psychic and somatic anxiety, early morning awakening and loss of libido, but some patients with depressive symptomatology and "reversible" NCD progress into irreversible NCD [38] [39] [40]. The domains and the constructs of Research Domain Criteria from the National Institutes of Mental Health, namely negative valence systems (loss) and cognitive systems (cognitive control), have been operationalized. Negative valence systems are primarily responsible for responses to aversive situations or context, such as fear, anxiety and loss. Loss is a state of deprivation of a motivationally significant con-specific, object, or situation, and may be social or non-social and may include permanent or sustained loss of shelter, behavioral control, status, loved ones or relationships. The response to loss may be episodic (e.g., grief) or sustained. Cognitive control is a system that modulates the operation of other cognitive and emotional systems, in the service of goal-directed behavior, when pre-potent modes of responding are not adequate to meet the demands of the current context, and, additionally, control processes are engaged 
in the case of novel contexts, where appropriate responses need to be selected from among competing alternatives. Response selection and inhibition/suppression are functions of cognitive control [41]. For the z-score analysis, the patient neuropsychological results (at "time 1") were compared with the reference sample, by age. After the completion of a cognitive stimulation/rehabilitation program (30 sessions, with three levels of difficulty) (at "time 2"), it has been verified, concomitant with decreased affective symptomatology, an improvement in executive/cognitive function, in particular, at planning, decision making, set shifting/cognitive flexibility and inhibitory control, which, index the re-assumption of the structural and functional integrity of PFC and OFC (Table 1 and Figure $1)$.

\section{Concluding Remarks}

A normal cognitive control of emotion, requiring the functional and structural integrity of prefrontal cortex (PFC) and orbitofrontal cortex (OFC), is lacking in depression, but its amelioration/remediation can be achieved through the implementation of cognitive remediation/rehabilitation programs. Computerized cognitive remediation through the induction of neuroplasticity and targeting brain networks, which sustains the cognitive control of emotion and clinical outcomes in disrupted negative valence systems and cognitive systems associated

Table 1. Longitudinal comparison of neuropsychological test scores in a patient with unipolar major depressive episode. Evidence of improvement of executive/cognitive function (planning, decision making, set shifting/cognitive flexibility and inhibitory control), concomitant with decreased affective symptomatology, in a 44 year-old female, acutely depressed, patient after her subjection to a cognitive remediation/rehabilitation program (at "time 2") (Note: HAM-D-17: 17 item Hamilton depression rating scale; FT-D: dominant hand from finger tapping task; FT-ND: non-dominant hand from finger tapping task; TOL-extra: extra moves from tower of London; IOWA-net score: net score from Iowa gambling task; WCST-PE: preservative errors from Wisconsin card sorting test; VStroop-Interf.: interference errors from Victoria Stroop task).

\begin{tabular}{|c|c|c|c|c|c|c|c|}
\hline \multirow[t]{2}{*}{ Measure } & \multicolumn{3}{|c|}{$\begin{array}{c}\text { “Time 1" } \\
\text { (“with" affective symptoms) }\end{array}$} & \multicolumn{3}{|c|}{$\begin{array}{c}\text { "Time 2" } \\
\text { (“without" affective symptoms) }\end{array}$} & \multirow[t]{2}{*}{$\Delta \mathrm{z}$} \\
\hline & Raw score & $p$-value & Percentile & Raw score & $p$-value & percentile & \\
\hline HAM-D-17 & 26 & - & - & 2 & - & - & - \\
\hline FT-D & 56 & 0.946 & $25-50$ & 58 & 0.862 & $25-50$ & 0.2 \\
\hline FT-ND & 52 & 0.719 & $50-75$ & 52 & 0.719 & $50-75$ & 0 \\
\hline TOL-extra & 19 & 0.211 & 10 & 12 & 0.858 & $50-75$ & 1.5 \\
\hline IOWA-net score & 14 & 0.766 & $10-25$ & 24 & 0.898 & $25-50$ & 0.4 \\
\hline WCST-PE & 33 & 0.229 & $<10$ & 9 & 0.397 & $25-50$ & 2.1 \\
\hline VStroop-Interf. & 3 & 0.146 & 25 & 1 & 0.861 & $25-50$ & 1.5 \\
\hline
\end{tabular}




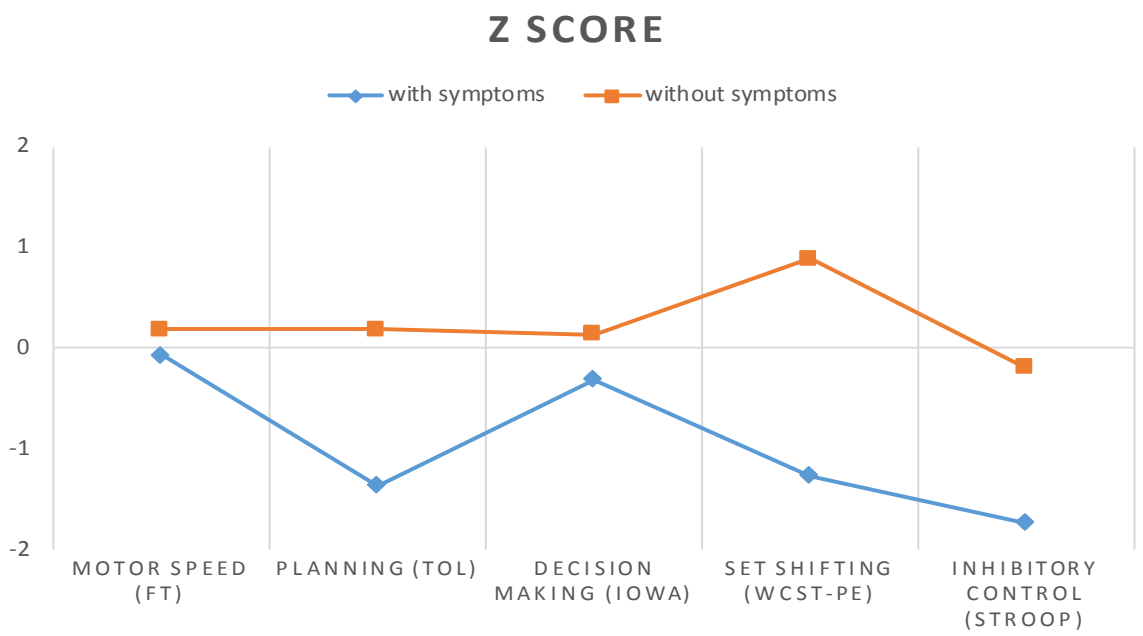

Figure 1. Graphical representation of longitudinal comparison of z score of performance of neuropsychological tasks concerning motor speed (FT), planning (TOL), decision making (Iowa), set shifting (WCST-PE) and inhibitory control (Stroop) in a patient with unipolar major depressive episode. Amelioration of planning, set shifting and inhibitory control after the completion of a cognitive remediation/rehabilitation program (Note: FT: dominant hand from finger tapping task; TOL: extra moves from tower of London; IOWA: net score from Iowa gambling task; WCST: preservative errors from Wisconsin card sorting test; Stroop: interference errors from Victoria Stroop task).

with loss/depression, has the potential to improve emotional/affective symptomatology.

\section{References}

[1] Suchy, Y. (2009) Executive Functioning: Overview, Assessment, and Research Issues for Non-Neuropsychologists. Annals of Behavioral Medicine, 37, 106-116. https://doi.org/10.1007/s12160-009-9097-4

[2] Gonçalves, E., Moniz, M. and Jesus, S. (2016) Assessment of Stress Cognitive Control and Executive Function with Stress Control Rating Scale (ECOSTRESS) and Low Resolution Brain Electromagnetic Tomography (LORETA) (In Portuguese People in Situations of Unemployment and Economic Insufficiency). Open Journal of Psychiatry, 6, 158-164. https://doi.org/10.4236/ojpsych.2016.62019

[3] Joormann, J. and Vanderlind, W.M. (2014) Emotion Regulation in Depression: The Role of Biased Cognition and Reduced Cognitive Control. Clinical Psychological Science, 2, 402-421. https://doi.org/10.1177/2167702614536163

[4] Joormann, J. and Gotlib, I.H. (2010) Emotion Regulation in Depression: Relation to Cognitive Inhibition. Cognition \& Emotion, 24, 281-298.

[5] Davis, R.N. and Nolen-Hoeksema, S. (2000) Cognitive Inflexibility among Ruminators and Nonruminators. Cognitive Therapy and Research, 24, 699-711. https://doi.org/10.1023/A:1005591412406

[6] Lantrip, C., Isquith, P.K., Koven, N.S., Welsh, K. and Roth, R.M. (2016) Executive Function and Emotion Regulation Strategy Use in Adolescents. Applied Neuropsychology: Child, 5, 50-55. https://doi.org/10.1080/21622965.2014.960567

[7] Niendam, T.A., Laird, A.R., Ray, K.L., Dean, Y.M., Glahn, D.C. and Carter, C.S. (2012) Meta-Analytic Evidence for a Superordinate Cognitive Control Network Subserving Diverse Executive Functions. Cognitive, Affective, \& Behavioral Neu- 
roscience, 12, 241-268. https://doi.org/10.3758/s13415-011-0083-5

[8] Etkin, A., Egner, T. and Kalisch, R. (2011) Emotional Processing in Anterior Cingulate and Medial Prefrontal Cortex. Trends in Cognitive Sciences, 15, 85-93.

https://doi.org/10.1016/j.tics.2010.11.004

[9] Etkin, A., Patenaude, B., Song, Y.J., Usherwood, T., Rekshan, W., et al. (2015) A Cognitive-Emotional Biomarker for Predicting Remission with Antidepressant Medications: A Report from the iSPOT-D Trial. Neuropsychopharmacology, 40, 1332-1342. https://doi.org/10.1038/npp.2014.333

[10] Miller, E.K. (2000) The Prefrontal Cortex and Cognitive Control. Nature Reviews Neuroscience, 1, 59-65. https://doi.org/10.1038/35036228

[11] Wager, T.D. and Smith, E.E. (2003) Neuroimaging Studies of Working Memory: A Meta-Analysis. Cognitive, Affective \& Behavioral Neuroscience, 3, 255-274. https://doi.org/10.3758/CABN.3.4.255

[12] Buhle, J.T., Silvers, J.A., Wager, T.D., Lopez, R., Onyemekwu, C., et al. (2014) Cognitive Reappraisal of Emotion: A Meta-Analysis of Human Neuroimaging Studies. Cerebral Cortex, 24, 2981-2990. https://doi.org/10.1093/cercor/bht154

[13] Cunningham, W.A., Van Bavel, J.J. and Johnsen, I.R. (2008) Affective Flexibility: Evaluative Processing Goals Shape Amygdala Activity. Psychological Science, 19, 152-160. https://doi.org/10.1111/j.1467-9280.2008.02061.x

[14] Hariri, A.R. and Whalen, P.J. (2011) The Amygdala: Inside and Out. F1000 Biology Reports, 3, 2. https://doi.org/10.3410/B3-2

[15] Ray, R.D., Ochsner, K.N., Cooper, J.C., Robertson, E.R., Gabrieli, J.D., et al. (2005) Individual Differences in Trait Rumination and the Neural Systems Supporting Cognitive Reappraisal. Cognitive, Affective \& Behavioral Neuroscience, 5, 156-168. https://doi.org/10.3758/CABN.5.2.156

[16] Rachle, M.E., MacLeod, A.M., Snyder, A.Z., Powers, W.J., Gusnard, D.A., et al. (2001) A Default Mode of Brain Function. Proceedings of the National Academy of Sciences USA, 98, 676-682. https://doi.org/10.1073/pnas.98.2.676

[17] D'Avanzato, C., Joormann, J., Siemer, M. and Gotlib, I.H. (2013) Emotion Regulation in Depression and Anxiety: Examining Diagnostic Specificity and Stability of Strategy Use. Cognitive Therapy and Research, 37, 968. https://doi.org/10.1007/s10608-013-9537-0

[18] Backenstrass, M., Frank, A., Joest, K., Hingmann, S., Mundt, C., et al. (2006) A Comparative Study of Nonspecific Depressive Symptoms and Minor Depression Regarding Functional Impairment and Associated Characteristics in Primary Care. Comprehensive Psychiatry, 47, 35-41. https://doi.org/10.1016/j.comppsych.2005.04.007

[19] Cohen, L.H., Gunthert, K.C., Butler, A.C., O'Neill, S.C. and Tolpin, L.H. (2005) Daily Affective Reactivity as a Prospective Predictor of Depressive Symptoms. Journal of Personality, 73, 1687-1713. https://doi.org/10.1111/j.0022-3506.2005.00363.x

[20] Fitzgerald, P.B., Laird, A.R., Maller, J. and Daskalakis, Z.J. (2008) A Meta-Analytic Study of Changes in Brain Activation in Depression. Human Brain Mapping, 29, 683-695. https://doi.org/10.1002/hbm.20426

[21] Harvey, P.O., Fossati, P., Pochon, J.B., Levy, R., Lebastard, G., et al. (2005) Cognitive Control and Brain Resources in Major Depression: An fMRI Study Using the n-Back Task. Neuroimage, 26, 860-869.

https://doi.org/10.1016/j.neuroimage.2005.02.048 
[22] Davidson, R.J., Pizzagalli, D., Nitschke, J.B. and Putnam, K. (2002) Depression: Perspectives from Affective Neuroscience. Annual Review of Psychology, 53, 545-574. https://doi.org/10.1146/annurev.psych.53.100901.135148

[23] Alexopoulos, G.S., Hoptman, M.J., Kanellopoulos, D., Murphy, C.F., Lim, K.O., et al. (2012) Functional Connectivity in the Cognitive Control Network and the Default Mode Network in Late-Life Depression. Journal of Affective Disorders, 139, 56-65. https://doi.org/10.1016/j.jad.2011.12.002

[24] Fox, M.D. and Raichle, M.E. (2007) Spontaneous Fluctuations in Brain Activity Observed with Functional Magnetic Resonance Imaging. Nature Reviews Neuroscience, 8, 700-711. https://doi.org/10.1038/nrn2201

[25] Gusnard, D.A., Akbudak, E., Shulman, G.L. and Raichle, M.E. (2001) Medial Prefrontal Cortex and Self-Referential Mental Activity: Relation to a Default Mode of Brain Function. Proceedings of the National Academy of Sciences USA, 98, 4259-4264. https://doi.org/10.1073/pnas.071043098

[26] Sheline, Y.I., Price, J.L., Yan, Z. and Mintun, M.A. (2010) Resting-State Functional MRI in Depression Unmasks Increased Connectivity between Networks via the Dorsal Nexus. Proceedings of the National Academy of Sciences USA, 107, 11020-11025. https://doi.org/10.1073/pnas.1000446107

[27] Greicius, M.D., Flores, B.H., Menon, V., Glover, G.H., Solvason, H.B., et al. (2007) Resting-State Functional Connectivity in Major Depression: Abnormally Increased Contributions from Subgenual Cingulate Cortex and Thalamus. Biological Psychiatry, 62, 429-437. https://doi.org/10.1016/j.biopsych.2006.09.020

[28] Ekin, et al. (2013) Neurobiology of Cognition in Psychiatric Disorders. Dialogues in Clinical Neuroscience, 15, 419-429.

[29] Lantrip, C. and Huang, J.H. (2017) Cognitive Control of Emotion in Older Adults: A Review. Clinical Psychiatry, 3, 1. https://doi.org/10.21767/2471-9854.100040

[30] Sousa, M.P., Lopes, J.S. and Vieira, R. (1979). Comparação entre a Escala de Hamilton e o questionário de Beck na quantificacão das depressões. Jornal do Médico, 103, 561-571.

[31] Hyler, S.E. (1994). Personality Diagnostic Questionnaire. New York State Psychiatric Institute, New York,

[32] Mueller, S.T. and Piper, B.J. (2014) The Psychology Experiment Building Language (PEBL) and PEBL Test Battery. Journal of Neuroscience Methods, 222, 250-259. https://doi.org/10.1016/j.jneumeth.2013.10.024

[33] Moniz, M., De Jesus, S.N., Viseu, J., Gonçalves, E., Pacheco, A. and Baptista, A.S. (2016) Planning Dysfunction in Non-Psychotic Unipolar Depressed Patients: Assessment by a Computerized Version of the Tower of London Task. International Journal of Psychological Studies, 8, 119-124. https://doi.org/10.5539/ijps.v8n1p119

[34] Moniz, M., De Jesus, S.N., Gonçalves, E., Pacheco, A. and Viseu, J. (2016) Decision-Making in Adult Unipolar Depressed Patients and Healthy Subjects: Significant Differences in Net Score and in Non-Traditional Alternative Measures. Neuropsychological Trends, 19, 7-15. https://doi.org/10.7358/neur-2016-019-moni

[35] Moniz, M., De Jesus, S.N., Gonçalves, E., Viseu, J., Baptista, A.S. and Pacheco, A. (2016) Computerized Victoria Stroop Test in Adult Unipolar Depressed Patients and Healthy Subjects: Influence of Age and Gender. Psychology, 7, 1-5. https://doi.org/10.4236/psych.2016.71001

[36] Moniz, M., De Jesus, S.N., Viseu, J., Gonçalves, E., Moreira, S. and Pacheco, A. (2016) Executive Dysfunction in Non-Psychotic Unipolar Depressed Patients: Assessment by the Wisconsin (Berg) Card Sorting Test. International Journal of Psychological Studies, 8, 112-118. https://doi.org/10.5539/ijps.v8n1p112 
[37] Moniz, M., De Jesus, S.N., Pacheco, A., Gonçalves, E. and Viseu, J. (2016e) Computerized Finger Tapping Task in Adult Unipolar Depressed Patients and Healthy Subjects: Influence of Age, Gender, Education, and Hand Dominance. Review of European Studies, 8, 1-10. https://doi.org/10.5539/res.v8n4p1

[38] World Health Organization (WHO) (2010) The $10^{\text {th }}$ Revision of the International Classification of Diseases (ICD-10).

http://apps.who.int/classifications/icd10/browse/2010/en\#/F00-F09

[39] American Psychiatric Association (APA) (2013) Diagnostic and Statistical Manual of Mental Disorders (DSM-5). 5th Edition, APA, Washington DC.

[40] Morimoto, S.S., Kanellopoulos, D., Manning, K.J. and Alexopoulos, G.S. (2015) Diagnosis and Treatment of Depression and Cognitive Impairment in Late Life. Annals of the New York Academy of Sciences, 1345, 36-46.

https://doi.org/10.1111/nyas.12669

[41] National Institutes of Mental Health (NIMH) (2017) Definitions of Domains and Constructs. Research Domain Criteria (RDoC).

https://www.nimh.nih.gov/research-priorities/rdoc/definitions-of-the-rdoc-domain s-and-constructs.shtml 